\title{
EDUCACIÓN Y LIBERACIÓN DESDE LA ÓPTICA \\ DE LeONIDAS PROAÑo
}

Education and liberation from

the perspective of Leonidas Proaño

\author{
JUAN ILLICACHI GUZNAY ${ }^{*}$ \\ Universidad Nacional de Chimborazo/ Riobamba- Ecuador \\ jillicachi@unach.edu.ec \\ Código Orcid: http://orcid.org/0000-000 1-6283-6290 \\ JORGE VALTIERRA ZAMUDIO ${ }^{* *}$ \\ Instituto Nacional de Antropología e Historia/México - México \\ jorge_valtierra_z@encrym.edu.mx \\ Código Orcid: http://orcid.org/0000-0003-3681-7867
}

\begin{abstract}
Resumen
El presente artículo se propone analizar la acción pastoral de Leonidas Eduardo Proaño, designado obispo de la Diócesis de Riobamba en 1954; en un contexto en el que la población indígena fue considerada como hombresobjetos, hombres-mercancías y hombres-monedas de cambio. En la actualidad aún se observa la persistencia, así como una constante emergencia del racismo y opresión en sus muchas facetas que incluyen la marginación de los grupos racializados; peor aún, los ataques públicos a las vidas y dignidad de las personas indígenas. A posteriori, el artículo rastrea en el campo de la Iglesia progresista y de las Escuelas Radiofónicas Populares del Ecuador (ERPE) con base en el diálogo con las cartografías teóricas de los filósofos Achille Mbembe, Michel Foucault y en el del pensador poscolonial Franz Fanon, las múltiples maneras de liberación, lucha y resistencia, concluyendo que ningún poder es infranqueable; donde hay poder hay líneas de fuga. El propósito es evidenciar la manera cómo opera, a la vez, los impactos estructurales y la agencia de una población históricamente oprimida, configurando otras formas de acción política en alianza con el obispo identificado con los hombres del poncho; o sea, con los hombres impedidos de ser hombres. La metodología que contribuye a desarrollar el presente trabajo consiste en la revisión de archivos y literatura especializada, entrevistas e historias de vida a fin de examinar los horizontes de liberación.
\end{abstract}

Palabras claves

Liberación, Iglesia progresista, Chimborazo, ERPE, educación.

Forma sugerida de citar: Illicachi Guzñay, Juan, \& Valtierra Zamudio, Jorge (2018). Educación y liberación desde la óptica de Leonidas Proaño. Sophia, colección de Filosofía de la Educación, 24(1), pp. 145-170.

* Doctor en Antropología Social. Maestría en Educación Superior. Maestría en Estudios Étnicos. Licenciado en Filosofía y Ciencias Socioeconómicas. Profesor investigador de la Universidad Nacional de Chimborazo y docente de la Universidad Técnica de Ambato.

** Doctor en Antropología Social. Magíster en Antropología Social. Licenciado en Historia. Miembro del Sistema Nacional de Investigadores del Consejo Nacional de Ciencia y Tecnología (Conacyt). Profesor-investigador en la Escuela Nacional de Conservación, Restauración y Museografía del Instituto Nacional de Antropología e Historia, en México. Catedrático en historia política y social de Europa en la Universidad La Salle, Ciudad de México. 


\begin{abstract}
This article analyzes the pastoral action of Leonidas Eduardo Proaño, appointed bishop of the Diocese of Riobamba in 1954; in a context in which the indigenous population was considered as men-objects, men-commodities and men-exchange currencies. Presently there is still persistence, as well as a constant emergence of racism and oppression in its many facets that include the marginalization of racialized groups; Worse, public attacks on the lives and dignity of indigenous people. A posteriori, the article traces in the field of the Progressive Church and the Popular Radio Schools of Ecuador (ERPE) based on the dialogue with the theoretical cartographies of the philosophers Achille Mbembe, Michel Foucault and the postcolonial thinker Franz Fanon, The multiple ways of liberation, struggle and resistance, concluding that no power is impassable; Where there is power there are lines of escape. The purpose is to demonstrate how the structural impacts and agency of a historically oppressed population operate, at the same time, forming other forms of political action in alliance with the bishop identified with the men of the poncho; That is to say, with men prevented from being men. The methodology that contributes to the development of the present work consists of the revision of archives and specialized literature, interviews and life histories in order to examine the horizons of liberation.
\end{abstract}

Keywords

Liberation, progressive church, Chimborazo, ERPE, education.

\title{
Introducción
}

El tema de la liberación o liberacionismo en América Latina ha generado opiniones encontradas, pues se ha relacionado mucho con posturas ideológicas como el socialismo y con una firme convicción en contra del capitalismo. Este tema, sin embargo, es más complejo que una postura política en particular y advierte la cuestión cultural e identitaria, por tratarse de un continente tan diverso en estos rubros.

El radicalismo con el que se ha identificado al sector de la Iglesia católica latinoamericana en este tenor liberador, tuvo su origen a finales de la década de 1960 y perduró con fuerza hasta la primera mitad de 1990, lo que no significa que haya culminado de manera definitiva, sobre todo como se ha insinuado, a partir del fin de la Guerra Fría. ${ }^{1}$ Esto se le conoce como Teología de la Liberación y consiste grosso modo en una posición crítica de la Iglesia católica hacia los modelos capitalistas que cobran gran fuerza a partir del periodo de posguerra $(1945)^{2}$.

Mucho se ha escrito sobre la teología de la liberación, su origen y su contenido, pero no es suficiente el análisis de las consecuencias o su proyección en épocas actuales, para comprender la naturaleza y objetivos de las pastorales alternativas y liberacionistas latinoamericanas. Sin embargo, las posibilidades de hacer un análisis sobre la teología de la liberación y su proyección son por demás complejas en un espacio como este, pues la diversidad de situaciones históricas, políticas, culturales, entre otras, en Latinoamérica es inmensurable. Es por eso que hemos de 
concentrarnos en un caso ejemplar que junto a otros en Centroamérica como Nicaragua, Guatemala o el sureste mexicano, es vital en el análisis de su praxis pastoral liberacionista. En este caso nos enfocaremos en la liberación a partir de la Iglesia católica en Chimborazo, Ecuador.

En esencia, el problema identificado en esta zona del Ecuador se relaciona con la diversidad cultural, inmersa en una problemática social generalizada de desigualdad adjudicada a la modernidad y los modelos políticos y económicos de corte capitalista. La liberación de la Iglesia a través de la teología de la liberación, asumió ante esto una postura general de liberación del pobre y el oprimido, pero en la praxis fue más reflexiva y autocrítica, al punto de entender, en casos como el de Ecuador y otros Estados latinoamericanos, la complejidad cultural de los pueblos indígenas y su derecho a la diferencia étnica.

La aceptación y adaptación de una pastoral en la diversidad cultural latinoamericana no sólo ha logrado que la "liberación" sobreviva, sino que se actualice, resignifique y reavive. ${ }^{3}$ Pero, ¿ cómo se ha dado continuidad a esa lucha por la liberación de los pueblos indígenas, en particular de los de Chimborazo, Ecuador? De ahí la importancia de conocer la catequesis y labor misionera del obispo Leonidas Eduardo Proaño Villalba.

El presente artículo es resultado de un análisis de los indígenas de Chimborazo que, sumidos en una situación de pobreza extrema provocada por el legado de la violencia colonial y racial orquestada por el gamonalismo $\mathrm{o}^{4}$ caciquismo y el colonialismo interno (González Casanova, 2006), son todavía considerados como hombres-objetos, hombresmercancías y hombres-monedas de cambio. Aún se es testigo de la persistencia del racismo en sus muchas facetas que incluyen la marginalización de los grupos culturalmente distintos. Asimismo, continúan los ataques públicos a las vidas y a la dignidad de la persona de los indígenas.

A partir de la acción pastoral de Proaño, su propuesta educativa y de alfabetización, se ha logrado sentar las bases de un proyecto que constituye una alternativa de liberación de la población indígena del dominio del gamonalismo o caciquismo y una liberación sin violencia con base en los postulados del Evangelio "revolucionario" que toma como referencia el modelo de la liberación del pueblo Israel de la dominación egipcia; todo esto a partir de las Escuelas Radiofónicas Populares del Ecuador (ERPE).

Entre las principales aportaciones que se pretenden señalar en este artículo, con base en el proyecto educativo de Proaño aún vigente, es una propuesta de liberación y resistencia política y epistémica desde los horizontes analíticos y teóricos de los filósofos Achille Mbembe y Michel 
Foucault, sin descuidar la acción política y filosófica inspirada desde la Iglesia progresista de Riobamba, Ecuador ${ }^{5}$.

\section{Contexto de la base educativa de Proaño hacia la liberación}

Versa un proverbio chino: "si haces planes para un año, siembra arroz; si haces planes para diez años, planta árboles; pero si haces planes para cien años, entonces, educa al pueblo". Lo que hizo el obispo de Riobamba, Leonidas Proaño, fue precisamente abrir posibilidades para que el pueblo desposeído y sin acceso a la educación pudiera cambiar su situación a través de la instrucción escolar. En este sentido, para Proaño el ser humano valía sobre todas las cosas, incluso más que la misma catedral:

Los sectores reaccionarios de Riobamba estuvieron en contra de monseñor. Un periodista le dijo una vez: "bueno, para qué ha venido, no hace nada en Riobamba, no hace nada por la catedral. Para usted todo es el indio, el indio, el indio" a lo que monseñor Proaño le respondió: "Jesús no construyó ni una sola capilla, ni una catedral y, para mí, un solo indio, vale más que una catedral (Encalada, 2016, p. 48).

El testimonio da cuenta de que la población indígena para la Iglesia progresista de Riobamba era muy importante. Los indígenas eran la razón de ser de una Iglesia que buscaba elevar a una condición de humanidad a estos individuos históricamente disueltos, marginados y, hasta cierto punto, "transformados en hombres-objetos, hombres-mercancías y hombres-monedas de cambio" (Mbembe, 2016, p. 27). Para sostener esta argumentación y la manera en cómo el gamonalismo local de Chimborazo reproducía las relaciones de fuerza, presentamos el anuncio del reparto de los indígenas (hombres, mujeres y niños), que alude más a un reparto de los "salvajes" y de los "infelices", una de las características del sistema esclavista:

Este recorte del Diario la Nación de 1878, fue subido a las redes sociales el 06 de enero de 2016, cuyo título es "Hoy reparto de indios". El texto transcrito se lee así:

El Ministerio de Guerra informa a la ciudadanía que los días 5 y 6 del mes en curso se entregan indios para utilización en estancias ganaderas. Las indias aún salvajes pueden ser útiles en tareas domésticas en las residencias de las familias porteñas. Es necesario destacar que la comportación de las indias dista de ser civilizadas por lo que es menester la adaptación de los infelices. 
También hay a disposición de los señores comerciantes y firmas de esta plaza, indios menores de edad. Los infelices aun careciendo complemente de las gracias de la civilización, pueden utilizarse con sumo provecho para mandados diversos. Los mismos no pueden ser enviados al exterior. El reparto de los salvajes se realizará gratuitamente en el Hotel de Inmigrantes, los días 5 y 6 de octubre de 8 de la mañana a 6 de la tarde (Rubén Patagonia).

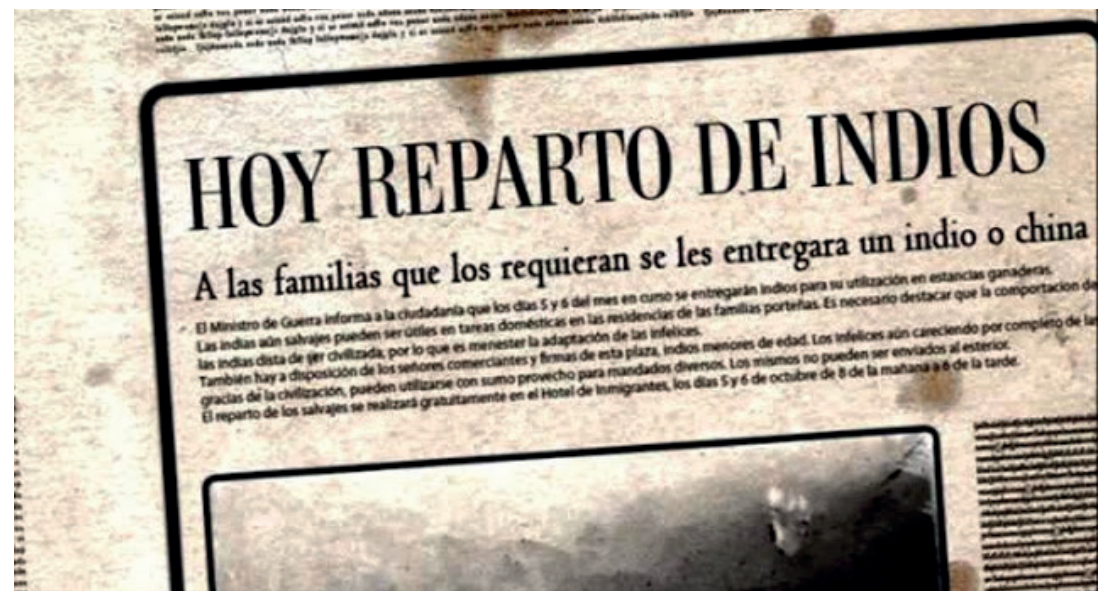

Fuente: Rubén Patagonia. Recorte del Diario La Nación. Octubre de 1878-Primera plana

Hoy, esta imagen histórica que el gamonalismo ${ }^{1}$ tenía sobre la población indígena se reforzó de muchas maneras; entre ellas se encuentran: el olvido ontológico (olvidar quiénes somos), el olvido epistemológico (olvidar lo que sabemos) y el olvido histórico (olvidar de dónde venimos) (Santos, 2010).

El anuncio en el Diario "La Nación" expuesto arriba es parte de la arqueología de un texto racista que representaba en ese momento una idea del indio o del indígena como "bárbaro", "infeliz", "salvaje", como aquel no-humano que sólo podía proveer -y aún lo hace en la actualidad en ciertos espacios- hombres-compra y venta, hombres-mercancía (Mbembe, 2016). En este anuncio de La Nación se salvajiza a los indígenas sin importar el sexo o la edad, un mecanismo por el cual la vida de los indígenas es catalogada como no-humana y es a su vez causa y efecto de las instituciones coloniales como la Iglesia, el Estado, las haciendas, entre otras, y estas mismas son a su vez causa y efecto de la denominada "infelización", "bestialización” o "salvajelización” (Fanon, 2011). 
El sujeto dominante reproduce toda una maquinaria de adjetivos y sustantivos en el momento de fabricar a ese "Otro" indígena, desacreditado y considerándolo como una otredad incapaz de ascender al estadio de la civilización. Parafraseando a Edward Said, se diría que la nota presentada evidencia la manera en que operaba u opera el orientalismo interno en el sentido de dar cuenta los mecanismos de construcción del Otro. Así, 'oriente' -como se definiría desde Said a la otredad- adquirió, adaptándolo en el contexto de Chimborazo, representantes y representaciones cada vez más concretas y coherentes con alguna exigencia occidental (2009, p. 97).

En los tiempos actuales no puede negarse la mutación que han sufrido las formas de explotación; es decir, sigue habiendo una práctica estructural colonial e imperial que "ensalvajan" y cosifican a los habitan150 tes del mundo, aunque con formas y discursos distintos, no distinguiendo un objeto de un individuo. De hecho, el filósofo camerunés Achille Mbembe (2016) lo expresa con mucha claridad; la distinción entre el ser humano, la cosa y la mercancía tiende a desaparecer, sin que nadie -indígenas, mujeres, hombres, blancos, negros, niños- pueda escapar de ello.

Las reflexiones de Mbembe en el contexto que analizamos demuestran que, tanto instituciones públicas como privadas, tejidas entre ellas, han sido partícipes de estas formas de explotación y que en realidad poco ha cambiado en esencia la situación expresada en el diario La Nación a finales del siglo XIX a la actualidad; por lo tanto, tampoco había cambiado en la época en que Proaño fue nombrado obispo de Riobamba, en la década de $1950 .^{6}$

La acción pastoral del obispo Proaño no estaba a favor de estas estructuras que generaban desigualdad y marginación. La manera de confrontarlo fue a través de la educación por medio de programas de alfabetización -Escuelas Radiofónicas Populares del Ecuador (ERPE)-, aunque con muchas limitaciones. Según Baylach, "no había nada para empezar, ni local, ni emisora, ni técnicos, ni maestros; sólo una hermosa idea" (1979). Sin embargo, la actitud acérrima y revolucionaria de Proaño pesó más que las limitaciones.

Este proyecto educativo de liberación comenzó a operar con objetivos precisos como los de evangelizar, concienciar y alfabetizar a los campesinos y, en particular, a los indígenas. En su labor pastoral, Proaño buscaba contribuir en el proceso de humanizar al deshumanizado, para que los "infelices" fueran "felices" y para que los "ensalvajados" fueran "desalvajizados". Los efectos de estos propósitos cobran fuerza cuando 
ERPE, en seno de la Iglesia Católica, salió al aire oficialmente entre marzo de 1962 y agosto de 1963.

Los estatutos de ERPE fueron aprobados por la junta constitutiva; es decir, se aprobaron sus operaciones como resultado de múltiples encuentros, debates, decisiones y gestiones desarrolladas al principio de la década de 1960. ERPE emergió como una alternativa a todo tipo de racismo, prejuicios, estereotipos y cacicazgos, en un momento en que iba fraguando la teología de la liberación en la Provincia de Chimborazo.

Hasta el momento a través de estas herramientas educativas a la par de coyunturas políticas e ideológicas como la liberación o liberacionismo de la década de 1960, se insinúa la base primordial de la labor pastoral de Proaño. Sin embargo, en muchos casos como Chimborazo y muchos más en América Latina y el mundo entero, la violencia colonial y racial en sus muchas facetas que atentan contra la dignidad humana de la población indígena, permanece en nuestros días. Analizaremos más estas circunstancias a continuación.

\section{Cuerpos y mentes excluidos}

A lo largo de la historia y la configuración de la sociedad latinoamericana, el contacto entre mestizos e indígenas en espacios como templos, municipios, universidades, mercados y calles ha sido inevitable. Estos son patrones históricos y sociales recurrentes en diversos países como México, Guatemala, El Salvador, Perú, Colombia o Ecuador. En estos encuentros la sociedad dominante se ha valido de mecanismos de control con un contenido racial con el que vigilaban por medio de la opresión a los sectores más desfavorecidos, principalmente a los indígenas. Para Hugo Burgos (1997) esto es el dominio económico y social sobre un grupo étnico y cultural que sirve de base para desalentar la integración de la estructura desigualmente tratada. En muchos espacios públicos y privados se visibiliza aún hoy el trato racializado y de discriminación:

Para citar sólo unos casos obsérvese lo que ocurre en el Palacio Arzobispal. Miércoles y sábados, especialmente, indios y cholos, así como blancos de las parroquias, recurren al Palacio en pos de una boleta que servirá para confirmar a los niños dentro de la religión católica. Todos los campesinos están sentados en la acera del parque Maldonado o en los zaguanes esperando que sean las dos de la tarde. Lastimosamente un miércoles de noviembre llovió con fuerza. Salió un portero e insinuó: "Entren a la sala de espera porque está lloviendo". Gran parte de los campesinos, cholos y mestizos no esperaron más y se dirigieron a la sala 
para guarecerse de la lluvia, pero al momento de intentar entrar los indios, el portero con buenas maneras les detuvo: "Deben quedarse afuera los rocotos porque la sala es muy estrecha". Los indios tuvieron que ir a guarecerse donde pudieron" (Burgos, 1997, p. 268).

Hasta hoy, el obispo de la Diócesis de Riobamba continuó teniendo atribución exclusiva de celebrar la denominada confirmación a los niños y jóvenes católicos a menos que él mismo autorice para que este "sacramento" sea celebrado por un sacerdote en las parroquias rurales y urbanas.

Si examinamos el dato empírico señalado con el ojo del filósofo Achille Mbembe (2011 y 2016), podemos decir que hay cuerpos y bios que no tienen valor. El cuerpo de los mestizos podía protegerse de la lluvia al entrar a la sala, mientras que el de los "rocotos"-como dice el portero- podían guarecerse en donde sea, pero no en el Palacio Arzobispal. La discriminación y el racismo del mestizo hacia el indígena funcionan en forma de necropoder, incluso hasta hoy.

El concepto de "necropolítica" desarrollado por Achille Mbembe en su obra "Necropolítica. Sobre el gobierno privado indirecto" y retomado en "Crítica de la razón negra", se refiere a la política basada en la idea de que para el poder unas vidas tienen valor y otras no ${ }^{7}$. No es tanto matar a los no sirven el poder, sino dejarlos morir; esto es, crear políticas en las que se van muriendo. Dicho en términos foucaultianos el racismo y discriminación opera en el esquema de hacer vivir y dejar morir. "Podría decirse que el viejo derecho de hacer morir o dejar vivir fue reemplazado por el poder de hacer vivir o de arrojar a la muerte" (Foucault, 2011, p. 128).

Desde la perspectiva de Mbembe y Foucault, el caso del indígena que no se le permitió el ingreso a la sala arzobispal puede analizarse desde el necropoder por el modo en que fue excluido y porque estos sujetos son los que no son rentables para la institución y estructura del poder. De nuevo, entonces, el poder no necesita matar a los que no sirven al poder, sino dejar morir; es decir, se borra el viejo derecho de matar. ${ }^{8}$ Tanto para el necropoder (Achille Mbembe, 2011) como para el biopoder (Foucault, 1996), el poder, parece funcionar al segregar a las personas que deben morir de que aquellos que deben vivir. Así, la exclusión sigue funcionando en diferentes campos y niveles como se observa en el siguiente testimonio:

Cuando yo estuve en el cuarto curso, vino al colegio una chica indígena de Colta a tercer curso. Ella llegó puesta una bayeta roja sobre el suéter del colegio, collar lleno de su cuello, todos quedaron mirando con sorpresa. Cuando se presentó habló con muchas interferencias lingüísticas, cambió la vocal "i" por la "e" y la "o" por la "u", Entonces ya empezaron a ver más aún como rara, inferior y con burla escondida. Ella ya empezó a sentirse 
excluida y de hecho la excluyeron. Me dolió mucho porque yo también pongo el anaco, pero no pude hacer nada para intervenir, a mí nunca me faltaron el respeto porque yo hablo bien el castellano. Creo que por eso fui la primera vicepresidenta indígena del gobierno estudiantil del año lectivo 2013-2014. Continuando con la historia, su pronunciación en el castellano le había hecho sentir súper mal, hasta había llorado. Prefirió no hablar mucho, creo que tenía miedo a equivocarse. La burla era disimulada pero la indiferencia le excluyó automáticamente. En el recreo pasaba sola. Cuando remedaron la pronunciación yo le miraba fijamente y bajaron la mirada. A ningún profesor le interesó ese caso, nadie habló sobre ese tema, para bien o para mal. En quinto y sexto curso ya dejó su vestimenta que trajo de Colta. Ya no vi con sus collares rojos ni bayeta. Su forma de vestir cambió casi en su totalidad, pero eso ayudó para estar en el grupo (Entrevista registrada por Illicachi, 2015, p. 107).

En este caso opera la necroeducación, entendida como una educación de la muerte; no porque los centros escolares sean campos de concentración; no porque los docentes, los del nivel administrativo o de servicios "maten" a sus alumnos; no porque los militares o policías entren armados a los campus colegiales a matar a los estudiantes, sino porque dejan morir a la gente ontológica, epistemológica e históricamente. En términos de Clara Valverde (2015) sería muerte en vida. "Hacer morir o dejar vivir" constituye, por lo tanto, los límites de la estructura triangular de la colonialidad: poder, saber y ser (Achille Mbembe, 2011; Mignolo, 2014).

En esta línea de reflexión, podemos señalar que el racismo, según Foucault (1996), no es simplemente la asignación de valores jerárquicos a una gama de expresiones fenotípicas tales como el cabello, el color de la piel y la forma de la nariz. El filósofo francés ve el racismo más como una red de inteligibilidad; como una gramática que no se refiere necesariamente a un determinado grupo de personas, sino a una división más generalizada dentro del cuerpo político (Nelson, 2006). La biopolítica selecciona el cuerpo y la vida. En y para la biopolítica no caben todos los cuerpos ni todas las vidas ni todas la personas. Hay personas que valen más y hay personas que valen menos de acuerdo al fenotipo, la vestimenta, los apellidos, la posición económica. Para sostener estas afirmaciones, en junio de 2017 se realizaron las siguientes preguntas a 414 personas al azar; no utilizamos ningún criterio para seleccionar a los sujetos encuestados, tomando en consideración la siguiente idea: "El sociólogo es aquel que va por la calle e interroga al primero que pasa; que lo escucha y aprende de él. Es lo que hacía Sócrates" (Bourdieu, 2008, p. 68). 
Encuesta sobre el racismo en Riobamba

\begin{tabular}{|l|c|c|c|}
\hline \multicolumn{1}{|c|}{ Preguntas } & $\begin{array}{c}\text { Respuesta: } \\
\text { Sí }\end{array}$ & $\begin{array}{c}\text { Respuesta: } \\
\text { No }\end{array}$ & Total \\
\hline ¿Ecuador es un país racista? & 381 & 113 & 441 \\
\hline ¿Riobamba es una ciudad racista? & 294 & 120 & 441 \\
\hline ¿Existe un racismo oculto o disfrazado? & 305 & 108 & 441 \\
\hline $\begin{array}{l}\text { ¿Usted en algún momento ha escuchado } \\
\text { discursos racistas? }\end{array}$ & 278 & 136 & 441 \\
\hline $\begin{array}{l}\text { ¿Usted en algún momento ha empleado } \\
\text { mensajes, palabras y discursos racistas? }\end{array}$ & 181 & 221 & 441 \\
\hline $\begin{array}{l}\text { ¿Usted se identifica como descendiente } \\
\text { del pueblo puruhua o indígena? }\end{array}$ & 249 & 165 & 441 \\
\hline
\end{tabular}

Fuente: Elaborado por los investigadores.

En el presente cuadro, el objetivo no es analizar a profundidad, sino evidenciar, en términos generales, la existencia del racismo, admitido por los mestizos de Riobamba. Aunque estas respuestas se presentan de forma ambigua y contradictoria, por un lado, la mayoría acepta la existencia de discursos y prácticas racistas, por el otro, la mayoría también cuando la pregunta induce a responder sobre sus prácticas. En este sentido se puede decir que el racismo funciona, a su vez, de forma abierta y oculta, ambigua y contradictoria, construyendo y destruyendo la identidad. El racismo borra cualquier punto en común entre el dominante y el dominado, se crea una relación de enemistad irreconciliable entre la naturaleza y la civilización, entre seres naturales y civilizados. El sujeto natural es como la naturaleza indomable (Achille Mbembe, 2011).

Frente a esta realidad, en el contexto de Chimborazo, los indígenas se resistieron de múltiples maneras. En los siguientes apartados se retomará el tema expresado al principio del artículo, a partir del análisis de esta situación de resistencia desde los proyectos de educación y liberación, tomando como escenarios de lucha las Escuelas Radiofónicas Populares del Ecuador (ERPE) y la Iglesia Progresista de Riobamba.

\section{ERPE en la "Iglesia de los pobres"}

ERPE se articula en el escenario de la llamada "Iglesia de los Pobres", decidida a vincular su acción pastoral a los intereses del campesinado (Bretón, 2001). La alfabetización para la Iglesia progresista era una prioridad, 
un acto de amor, de coraje, un camino hacia la libertad, una práctica de la misma libertad (Freire, 2013) y un compromiso con el Evangelio. Resulta clara la matriz conceptual en la que emergen las Escuelas Radiofónicas Populares del Ecuador (ERPE) con un acento profundamente eclesial a los sectores más progresistas de la iglesia de la década de 1970.

Monseñor Luna Tobar, otra de las personalidades más representativas de la Teología de Liberación en América Latina, en el prólogo del libro "Por una iglesia liberadora" (Gallegos y García, 2010) menciona que de la historia pastoral de monseñor Proaño se descubre en él una insistente búsqueda de luz que recuerda la petición del ciego de Jericó. Pero no era una búsqueda de alumbramiento para el más allá, para la inexistencia, sino una búsqueda para hoy y para el hombre de "carne y hueso".

ERPE, con la instalación de la emisora y del equipo de estudio se inaugura oficialmente el 19 de marzo de 1962 e inicia operaciones con diez escuelas a fin de cumplir con el objetivo de alfabetizar preferentemente a los campesinos adultos. La alfabetización contribuye "a dar luz al ciego de Jericó encarnado en los indígenas".

La construcción del bloque cultural ${ }^{9}$ (Radiofónicas, centros de formaciones y organizaciones indígenas) para la Iglesia de los pobres y la población indígena no era una tarea fácil; uno de los recursos limitantes fue la falta de financiación, como se asevera en el siguiente testimonio:

Hubo que recorrer un largo y doloroso calvario. No contábamos con medios financieros requeridos. Pedí ayuda a quienes podían dármela en la misma provincia de Chimborazo. Conseguí muy poco. Empezaron más bien las críticas. Pedí limosna en compañía de dos sacerdotes de la Diócesis en las puertas de las iglesias de Colombia, después de haber explicado la necesidad y el proyecto. También fue insuficiente el dinero que conseguí por este camino. Hubo que acudir a organizaciones extranjeras que empezaban a prestar ayuda a proyectos de desarrollo (Entrevista, Modesto Arrieta, sacerdote, octubre de 2016).

Ya puesta en operación, la radio educativa (ERPE) da abiertamente la palabra a la gente, por medio de la educomunicación popular. Las voces silenciadas inician a resurgirse de forma explícita. Cuestionan la cultura del silencio para dar paso a la cultura oral, de la palabra y de la escritura. Las voces surgen en kichwa y castellano. Para varios indígenas, ERPE se constituye en una de las experiencias básicas de la institucionalización de la Educación Intercultural Bilingüe, como se evidencia en una de las secciones del fundamento del Modelo del Sistema de Educación Intercultural Bilingüe (MOSEIB). En este sentido, ERPE es el locus de 
enunciación, de disputa y de resistencia frente a la jerarquía y el caciquismo que pretendía no solo naturalizar la dominación sino fortalecerla.

En este medio de comunicación educativo la palabra del oprimido, en vez de reproducir la ideología alienante, se convierte en generadora e instrumento de una transformación auténtica de hombre (Freire, 2013). Grupos de indígenas, campesinos, mujeres, jóvenes hacen talleres de producción radiofónica. Confeccionan sus propios programas, sus propios mensajes y resurgen temas étnicos como la cosmovisión, filosofía indígena, teología india, Pacha Mama (madre tierra), entre otros.

ERPE surge como un campo de lucha frente a la necroepistémica, porque, en la soberanía epistémica reside el poder y la capacidad de decidir cuál de los conocimientos puede vivir y cuál debe morir. "Hacer morir o dejar vivir constituye, por tanto, los límites de la soberanía, sus principales atributos" (Achille Mbembe, 2011, p. 20).

La expresión última de la estructura epistémica reside ampliamente en el poder y la capacidad de decidir cuál de los conocimientos puede vivir o cuál de los conocimientos debe morir, cual tiene que ser visible y cuál no (Achille Mbembe, 2011). Parafraseando a Michel Foucault (2010), podemos decir que el biopoder parece funcionar segregando los conocimientos de la gente -en el primer apartado habíamos dicho, segregando personas- que deben morir de aquellas que deben vivir. Pareciera incluso normal que el saber universal consista en la voluntad y capacidad de matar para vivir. Su lógica es matar para vivir, de lo contrario condena su existencia. Este tipo de exterminio epistémico puede hallarse también en la expansión colonial, pero también, se constituye en una estructura que sigue en pie tras el periodo de colonización. Achille Mbembe (2011) sostiene que la necropolítica devela lo que Foucault por medio del biopoder no pudo revelar, por ejemplo, nuevas formas de dominación, sumisión y tributo, en particular, en el continente africano poscolonial, aunque este postulado puede expandirse a los escenarios geopolíticos poscoloniales como Chimborazo.

Como contrahegemonía, ${ }^{10}$ los locutores y educadores kichwas de ERPE, al crear las condiciones necesarias podían por primera vez hablar abiertamente y con orgullo étnico sobre su Pacha Mama, Pachakutik, sobre sus líderes y sobre los saberes del sur. Esto implica el resurgimiento de escuchar la voz históricamente distorsionada, borrada y desdibujada de la historiografía hegemónica (Restrepo, 2005).

"Escuchar la voz" del subalterno en tanto sujeto-agente de su propia historia implicaba metodológicamente una "lectura en reversa" de las distorsiones propias de aquella pro de la contrainsurgencia que había 
sido amplificada por la historiografía elitista (Rodríguez, 1998 citado en Restrepo, 2005, p. 177).

Para varios indígenas por medio de la radio y voz concientizadora pone en serio peligro las diferentes esferas - parafraseando a Pierre Bourdieu (1996)- de la producción cultural hegemónica: arte, literatura, filosofía y cosmovisión. En este sentido ERPE es un medio y horizonte de emancipación política y epistémica para aquellos agentes indígenas oprimidos que la construyen y la reivindican. Es evidente que este medio educativo "rechaza el inmovilismo, la apatía y el silencio" (Freire, 2013, p. 25), incluso, denunciando con valentía la situación de injusticia y pobreza en que vivían los indígenas. La clave es la liberación, de lo que se hablará a continuación.

\section{Liberación en el pensamiento de Proaño}

La palabra liberación, etimológicamente proviene del latín libertio. Según el diccionario de la Real Academia de la Lengua Española (REA) la liberación es la acción de poner en libertad, lo que puede referirse a independencia o emancipación. La palabra liberación dentro del lenguaje coloquial se emplea para dejar claro que alguien se ha quitado un peso de encima, una carga que tenía en su interior y que le preocupaba. ${ }^{11}$

Proaño (1974) señala que la palabra liberación es muy utilizada por toda clase de personas y advertía que corre el peligro de ser utilizada por toda clase de personas y en muy diversos sentidos, sembrando así el desconcierto, confusión, y desconfianza. Uno de los riesgos es que utilicen la categoría liberación simplemente con confines económicos:

Si se habla de liberación únicamente pensando en las esclavitudes económicas, nos encontramos frente a un concepto parcial de liberación, frente a una dimensión que no abarca la totalidad del hombre. Si pensamos en cambio en que las esclavitudes económicas, las esclavitudes sociales, las esclavitudes psicológicas y otras, están mutuamente implicadas, porque tienen una misma raíz, entonces nos encontramos frente a un concepto total de liberación y frente a una dimensión que abarca todas las realidades del hombre (Proaño, 1974, p. 46).

Pero quien interviene en la liberación es la divinidad, es Jesús, el liberador de los hombres, pero no por eso niega la capacidad de la agencia de las personas ni sólo propone una liberación espiritual. 
En el contexto latinoamericano, el concepto liberación se desarrolla junto a la teología y filosofía, constituyéndose como la teología de la liberación de la que ya se ha hecho alguna mención en la introducción de este artículo. Al decir de Juan José Tamayo (2000), la teología de la liberación surge en América Latina, un continente pobre y en su mayoría cristiano en la década de los años sesenta. Uno de los planteamientos centrales de ésta es la libertad de los seres humanos que están oprimidos por otros.

En este andarivel de lucha por la liberación se insertan, fundamentalmente, algunos sacerdotes, obispos y laicos católicos. A finales de la década de 1960 emergieron no solamente acciones de liberación, sino expresiones como "irrupción de los pobres", "despertar de los oprimidos", "irrupción del sur en la historia”. En este sentido, no sólo son expresiones retóricas, sino que hacen referencia a uno de los fenómenos más significativos de nuestra historia reciente (Tamayo, 2000). Además, la II Asamblea General del Episcopado Latinoamericano, celebrada en Medellín (1968), sustituyó la categoría desarrollo por la liberación: ${ }^{12}$

Es obligado referirse al importante papel jugado por la educación liberadora ("pedagogía del oprimido"), del pensador brasileño Paulo Freire, que tuvo una amplia y profunda penetración en todo el subcontinente e influyó sobremanera en el paradigma de evangelización liberadora propuesta por Medellín y desarrollado posteriormente por una parte de la Iglesia Latinoamericana (Tamayo, 2000, p. 33).

El objetivo de la presente sección no es profundizar ni detenerse en la arqueología ni genealogía de la categoría "liberación", pero sí esgrimir como un andamiaje para entender la manera en que el obispo Leonidas Proaño empleó la teología y el evangelio para denunciar la opresión y acompañar en la lucha de la liberación de los oprimidos en la región de Chimborazo. De ahí que sea vital comprender la noción bíblica de éxo$\mathrm{do}^{13}$ en la liberación.

La palabra éxodo proviene del griego "éxodos" que significa salida o emigración de un pueblo. El éxodo también implica migración cuando hay desplazamientos dentro de las fronteras o emigración cuando estos ocurren de un país a otro. En términos bíblicos el Éxodo es el segundo libro de la Biblia en el Antiguo Testamento y el corazón del mismo que narra la esclavitud de hebreos en el Antiguo Egipto y su liberación a través de Moisés que los llevó hacia la tierra prometida (Ramos, s/a). Según la entrevista realizada al catequista Joaquín Pintag (Entrevista, catequista indígena, febrero de 2017), la palanca de la liberación para la Iglesia de 
Riobamba no es el marxismo ni el comunismo, como se ha manejado en sectores más conservadores de la Iglesia, sino el Éxodo, pues implica: "ante todo la liberación de los esclavos y la elección del pueblo de Israel. Es una liberación auténtica que alcanza a toda la realidad humana, individual y social: Dios libera a los que quieren tomar para sí, y la libertad cristiana estará muy lejos de lo que la cultura occidental entiende con esta palabra" (Biblia, 2005, p. 68).

El Éxodo es una radiografía de la liberación del pueblo israelita conducida por Moisés, "salvado de las aguas". Moisés es una figura reconocida como un profeta en el cristianismo, el judaísmo y el Islam. Para José Tamayo (2000), el éxodo bíblico ocupa un lugar central en los teólogos latinoamericanos de la liberación. Se trata de uno de los temas bíblicos más ligados a la TL.

La teología y los documentos teológico-pastorales relacionan con frecuencia la experiencia de opresión (Egipto) / liberación (éxodo) del pueblo de Israel con las experiencias de opresión / liberación de América Latina, sin que ello suponga identificar ambas situaciones o hacer transposiciones miméticas de una a otra. El éxodo bíblico aparece como motivo impulsor de la praxis histórica, o como paradigma de liberación para el Tercer Mundo hoy y como foco que ilumina los procesos históricos emancipadores (Tamayo, 2000, p. 110).

El concepto de liberación se constituye en una de las columbras vertebrales para los teólogos de la liberación, para la iglesia progresista, sobre todo, en el espacio de Chimborazo para el obispo Leonidas Proaño. La acción Israelita es un horizonte de inspiración de acción política y movilizadora. ${ }^{14}$ Metafóricamente se puede decir que el opresor (Egipto) es el gamonalismo de Chimborazo y los oprimidos (Israel) los indígenas o los campesinos; mientras el liberador (Moisés), inspirado en Dios, es Proaño, aunque él nunca se identificó o se definió como Moisés, antes bien se consideraba un estudiante del pueblo:

Quiero hacerlo, reconociendo, con sencillez, que cuanto he vivido y aprendido no ha sido extraído de las aulas universitarias de mí país o de algún otro país del mundo, sino de la cantera del pueblo, porque mi universidad ha sido el pueblo y mis mejores maestros han sido los pobres en general y particularmente los indígenas del Ecuador y de América Latina, considerados en Puebla como "los más pobres entre los pobres" (Archivo de CEDESA).

Para Leonidas Proaño la liberación de los israelitas era un modelo y referente de liberación, una liberación bíblica, divina y real, a la vez. Por 
lo tanto, la liberación de un pueblo oprimido no es un mandato humano, sino de Dios. Es el pueblo de Dios, quien tiene que liberarse del sometimiento y de unas condiciones de vidas inhumanas.

La liberación es una acción que determina la salida de una situación contraria a la dignidad del ser humano, pero la liberación no es espiritual, no es una liberación de los pecados, la liberación que propone Proaño es una más compleja que consiste en liberar política, económica y culturalmente. Incluso, la misma Iglesia tiene que liberarse de su alienación, de sus haciendas, de los partidos políticos dominantes, porque "la Iglesia ha sido aliada de los partidos llamado católicos compuestos muchas veces por oligarcas y opresores" (Proaño, 1974, p. 52). No es una liberación para el más allá, sino en este y para este mundo, ni es una liberación solitaria, sino colectiva y pacífica en que caminan, a la vez, todos

160 y todas, y el camino de la liberación no es lineal, sino en forma de zigzag, contiene rajaduras, rupturas, (Walsh, 2017) avances y retrocesos; de esta manera, se puede decir que el pensamiento y praxis de Proaño no es un nuevo dogma al margen de todo tiempo y espacio (pacha).

\section{Líneas de fuga para la liberación}

De acuerdo a los archivos del Centro de Solidaridad Andina (CEDSA) el programa de educación desarrollado por Proaño no sólo consistía en liberar a los oprimidos, sino también a los opresores. La clave, no es una liberación uniforme sino una multidimensional. Un proceso de autoliberación y reconocimiento en todos los niveles reticulares significa más que una independencia. Para este objetivo, lo que hizo la Diócesis de Riobamba es contribuir con los medios y recursos materiales necesarios, con la organización logística, preparación del personal docente y materiales didácticos.

Liberarse de sus opresores, relativamente podría resultar "fácil", pero liberarse de sí mismo y de su subjetividad oprimida es mucho más complejo. Para la liberación de los oprimidos y de los opresores, las peguntas recurrentes para Leonidas Proaño eran “ $¿$ Cómo despertar la sensibilidad de nuestros hermanos insensibilizados a fuerza de dolor y de sufrimientos incontables? ¿Qué hacer para despertar en ellos aspiraciones de superación y esperanzas de un futuro menos tenebroso? ¿Cómo hacer para que en su corazón empiece a nacer el amor a la vida y, por lo mismo, el amor a la lucha?" ¿Cuáles son los mecanismos y estrategias de liberación para los oprimidos?

La línea de fuga hacia la liberación es de doble vía: opresores y oprimidos, y no existe una sola respuesta ni formula única. En el presente 
apartado trataremos de responder desde diferentes cartografías teóricas, sin alejarse de la propuesta de Leonidas Proaño. Por ejemplo, para Clara Valverde (2015) parece que la liberación no sólo debe surgir de los oprimidos, sino también de la contribución de los opresores en el proceso de liberación. Valverde (2015) propone una empatía radical en el sentido de ponerse en el lugar del Otro, del oprimido y del que sufre. Es lo que Proaño hizo, vivir en lo que los indígenas vivieron y mostrar al Otro que el sufrimiento de los indígenas les importaba mucho. "Proaño no era de oficina, era de la realidad. Generalmente, pasaba en el campo con los indígenas, en sus reuniones, mingas, luchas, educación" (Entrevista a Joaquín Pintag, catequista, mayo de 2017).

La empatía radical no es sólo imaginarse e interesarse por el sufrimiento del Otro, sino también darse cuenta de que el Otro no es tan diferente de nosotros (Valverde, 2015); o sea, "nadie es superior ni inferior, todos somos iguales" (Entrevista, Tamya, directora del coro católico, mayo de 2017). Ningún grupo es más humano que los otros (Agamben, 2010), postulados que también circulaban en las acciones pastorales de Proaño.

Valverde (2015) sostiene que para rebelarnos frente a la opresión, la clave es la empatía radical que no es lo mismo que la tolerancia, porque quien tolera es porque tiene poder sobre ese sujeto, lo tolera porque ve menos al tolerado. La tolerancia es violenta y reproduce la exclusión, mientras la empatía radical consiste en tomar conciencia de que uno es también el que no tiene educación, los hijos de uno no tienen educación; por eso, este concepto se vuelve insurgente y antídoto de la opresión.

$\mathrm{Al}$ igual que Proaño, Valverde sugiere unir y frente al poder que quiere atomizar. Con esta propuesta Proaño funda algunas organizaciones indígenas: en 1972 Ecuador Runakunapak Richarimuy (ECUARUNARI), en 1982 la Confederación de Movimiento Indígena de Chimborazo (COMICH), en 1986 la Confederación de Nacionalidad Indígenas del Ecuador (CONAIE) y en 1964 ERPE. Proaño cohesiona a los indígenas, mujeres, campesinos y jóvenes a través de estas organizaciones de alcance regional y nacional. Ciertamente, ERPE y estos movimientos indígenas vehiculizan al desarrollar una empatía radical porque es un espacio de los excluidos, como diría Clara Valverde (2015). Es muy difícil que los incluidos inviten a los excluidos a sus movimientos, aunque los incluidos pueden en algún momento ser parte de los excluidos.

En este contexto del análisis y de la búsqueda de líneas de fuga para la liberación parece interesante también la propuesta de Frantz Fanon, quien propone liberar tanto al opresor como al oprimido, porque ambos 
son prisioneros: el blanco de su prejuicio y el negro del color de sí mismo. Ambos tienen que liberarse:

Se trata del problema del hombre y la mujer negros y de la búsqueda de liberación en un mundo dividido en dos: blanco y negro, por un mecanismo que él, sin ambages identifica como sistema colonial. Fanon quiere desamarrar y soltar a ambos de su prisión: al blanco de su prejuicio y al negro del color de sí mismo, para poblar ese espacio vacío, estéril, árido, esa cuesta despoblada, y borrar las aberraciones afectivas de uno y otro, esas dos metafísicas que generan relaciones excluyentes, unas radicales, y otra piadosas y paternalistas (Zapata, 2017, p. 28).

Similar a esta propuesta de liberación, en el contexto donde se desarrolló la presente investigación, Monseñor Leonidas Proaño, uno de los máximos representantes de la teología de la liberación en América Latina, señala que los ricos también son dominados, porque viven esclavos del dinero y de sus placeres. Por el mismo hecho de ser dominadores, ellos también son dominados. Según Proaño (1974), todos somos esclavizados por algo. Los medios y caminos de liberación que propone Proaño son diferentes a los de Fanon. Por ejemplo, el primero toma como modelo de liberación la salida de Israelitas de Egipto por medios pacíficos y pondera a Jesús como el liberador de los hombres; mientras Fanon (2011) considera a la liberación como un proceso violento ${ }^{15}$ y hasta doloroso; la descolonización es siempre un fenómeno violento. ${ }^{16}$ Frente a este planteamiento, Immanuel Wallerstein (2010) supone que el lector se pregunta a sí mismo si esta es una observación analítica, o si es más bien una recomendación política. La respuesta puede inclinarse con mayor peso a que la intención es que sean las dos cosas a la vez. Wallerstein (2010) sostiene que tal vez ni el propio Fanon está muy claro de cuál de los dos sentidos tiene prioridad. Y tal vez esto para Fanon no tiene importancia. Lo cierto es que Fanon abre surcos para la liberación o descolonización.

Por su lado, de acuerdo con los planteamientos de Michel Foucault, la manera principal de derribar aquellos elementos que tienden a dominarnos y suprimirnos, tendría que partir de la construcción de sujetos individuales que luchen esencialmente contra los diversos discursos constituyentes que tienden a constituirnos y donde el biopoder ha jugado un papel preponderante en la elaboración de discursos dominantes. No obstante, la tarea principal no consistiría en liberar al individuo del macro y/o micropoderes, sino liberar de ambos, de la estructura y del tipo de individualización que está liga a éste. Dicho en otras palabras, tendríamos que promover nuevas formas de subjetividad a través del rechazo de este 
tipo de individualidad que nos han impuesto durante siglos. O sea, si continuamos enseñando desde niños que hay humanidades superiores e inferiores, difícilmente habría una liberación ni "hoy", ni mañana, pues, es necesaria una ontología de la educación que preocupe por lo que sucede "aquî" y "ahora", y que responda a los interrogantes de los hombres de hoy (Higuera, 2014) que gritan por la libertad, hombres y mujeres, sujetos conscientes y responsables de sus actos y capaces de perfeccionarlos dentro del ejercicio de su autonomía (Ortega y Fernández, 2014).

Esta forma de ontología educativa contribuye en el proceso de la liberación de la idea de clasificar a los cuerpos, ayuda a desnaturalizar las construcciones sociales y mentales de dividir a mujeres y hombres "de primera" y "de segunda", "hombres civilizados y salvajes"; al menos para Proaño, "todos los hombres son iguales ante los ojos de Dios".

Se puede esgrimir como una "caja de herramienta" la filosofía crítica de Foucault para combatir contra la "presunta normalidad" de nuestro presente con la intención no solamente de denunciar, sino también de hacer emerger un pensamiento distinto, un pensar de otro modo (Lechuga, 2007) y digamos en términos de Proaño, un pensamiento desde los indígenas. Lo que hizo la Iglesia progresista de Riobamba es visibilizar los conocimientos históricamente sepultados, por ejemplo, cuando considera el pensamiento indígena como un tesoro:

El título de "doctor honoris causa" es un don que se me concede gratuitamente. Entre amigos y hermanos es normal que se establezca una correspondencia: el agraciado con un don está llamado a corresponder con otro don a los generosos donantes. En mi caso concreto, quiero ofrecerles el don que a mí me ha enriquecido: el tesoro del pensamiento y de las enseñanzas de los indígenas (Proaño, 1989, p. 5).

Este discurso es pronunciado en la Universidad de Saarland, Alemania Federal, el 26 de octubre de 1987 con motivo de recibir el doctorado Honoris Causa. En términos foucaultianos (2006), Proaño produce lo que podríamos llamar la insurrección de los saberes sometidos, provoca la insubordinación de los saberes descalificados por la jerarquía de los conocimientos y las ciencias (Foucault, 2006 y 1996). Por tanto, para Proaño la liberación no es solamente del hombre oprimido sino la liberación de la filosofía, cosmovisión y cosmovivencia indígena.

Así, la liberación que vehiculiza Proaño es integral y compleja. Es más, Proaño diagnostica el presente, su presente, su actualidad por medio de la Iglesia, de ERPE, movimientos indígenas, es decir, problematiza nuestra actualidad, preguntándonos ¿Qué somos? ¿Cómo escapar a eso 
que somos? ¿De qué manera trazar la línea de fuga que nos permita escapar a los mecanismos de saber y poder? (Márquez, 2007). El objetivo no es solamente descubrir qué somos, sino rechazar lo que nos han construido e inventado. Desechar una imagen postiza que parece inmanente. Cuestionar ontológicamente, también implica "¿quién soy yo?, ¿soy, en realidad, aquél que dicen que soy?, ¿es verdad que yo no soy otra cosa más que eso -es decir, mi parecer, lo que se dice y se ve de mí-?, ¿Cuál es mi verdadero estado civil e histórico?” (Achille Mbembe, 2016, p. 68). Estas problematizaciones pueden ser consideradas como una insurrección y liberación filosófica, epistémica y ontológica.

Los análisis del filósofo francés Michel Foucault sobre la resistencia contribuyen para examinar y comprender la resistencia de los indígenas de la región de Chimborazo frente a las diferentes formas de dominación 164 que produce el ejercicio del poder. Para este filósofo, el poder nunca es enteramente controlado por alguien o algunos, a cada instante se diseñan nuevas salidas en los juegos de poder. La palabra clave para entender los juegos de poder y evitar caer en la dominación es la resistencia, pues donde hay poder hay resistencia (Foucault, 2008). Hay resistencia cuando alguien dice "no", cuando se opone a una situación determinada con la intención de modificarla o bien evitarla.

La red social está atravesada por puntos de resistencia que tampoco son fijos, sino que pueden moverse rápido y actuar en grupo, o de manera individual por medio de la concertación o de manera imprevista. "La resistencia es tan inventiva, móvil y productiva como el poder, es coextensiva y contemporánea al poder y, como él, se distribuye estratégicamente. Donde hay poder existe la posibilidad de resistencia que es el "elemento irreducible enfrentador" (Lechuga, 2007, p. 120). En Chimborazo, por ejemplo, siempre se ha expresado la resistencia indígena, nunca ha habido pasividad total. Más concretamente, los debates teóricos en torno a la noción de resistencia no sólo tienen actualidad y vigencia, sino que contribuyen a explorar, analizar cómo los indígenas de Chimborazo se resisten, negocian y se acomodan frente al colonialismo interno ${ }^{17}$. La búsqueda de líneas de fuga y horizontes de liberación en la población indígena en la región de Chimborazo es ha sido y continua siendo un grito permanente.

\section{Conclusiones}

Los indígenas kichwas de Chimborazo, víctimas del racismo, dominación, explotación y humillación ejercido desde el poder gamonal, 
encontraron la "protección" y acompañamiento de la Iglesia progresista de Riobamba. Todo tipo de derechos negados por los partidos políticos, por la misma Iglesia católica tradicional y el sistema judicial (re)surgen y cuestionan a un poder que no sólo arrastra "la herencia colonial" de sus dispositivos, sino que contribuye a reforzar la hegemonía cultural, económica y política, incluso de occidente (Castro-Gómez, 2014). Ante todo, la Diócesis de Riobamba, vinculada a la teología de la liberación, se presenta como progresista en la medida en que hace las veces de línea de defensa y acción política contra la dominación gamonal. Esta insurgencia filosófica y política desde los movimientos indígenas inspirado en los proyectos educativos de la Curia "revolucionaria" no pretende actuar fuera del Estado o desde los márgenes (Illicachi, 2015).

De acuerdo a datos de la investigación, el racismo y las discriminaciones en la región de Chimborazo y el país no es un asunto del pasado no obstante de la declaratoria constitucionalmente como un Estado plurinacional e intercultural; sin embargo, pocos son los que conocen sus fuentes y las maneras en que se han instalado en la mentalidad colectiva a lo largo de la historia riobambeña, hasta convertirse en un sentimiento hegemónico (Gómez, 2006). Mientras en la práctica circulen el biopoder, biopolítica, necropolítica y necroepistémica aún tiene vigencia y utilidad el pensamiento de liberación de Proaño y de descolonización de Fanon no solamente para los indígenas, sino para toda una población subalternizada.

Leonidas Proaño, considerado uno de los máximos exponentes de la teología de la liberación en América Latina, confeccionó organizaciones indígenas de cohesión e instituciones de comunicación y educaciónalfabetización como las Escuelas Radiofónicas Populares del Ecuador a fin de contribuir en el proceso de revitalización étnica, despertar indígena, concientización y liberación en la región de Chimborazo.

Para seguir el chakiñan (camino) de la liberación parece interesante y fundamental esgrimir "como una caja herramienta" la propuesta teórica y filosófica de resistencia y lucha de Michel Foucault, Achille Mbembe, Franz Fanon y Leonidas Proaño, sin restar la importancia de otros teóricos. Así, tendríamos que promover nuevas formas de subjetividad a través del rechazo de tipo de individualidad que nos han impuesto durante siglos.

Para la acción pastoral de Leonidas Proaño, no es una liberación para el más allá, sino en este y para este mundo, ni es una liberación solitaria sino colectiva, no es violencia sino pacífica. Caminan, a la vez, todos y todas. El camino de la liberación no es lineal, es en forma de zigzag, contiene rajaduras, rupturas, (Walsh, 2017) avances, retrocesos, de esta 


\section{manera se puede decir que el pensamiento y praxis de Proaño no es un} nuevo dogma al margen de todo tiempo y espacio (pacha).

\section{Notas}

1 El "radicalismo" de la Iglesia católica en las épocas que hacemos referencia, se le ha tachado de marxista por parte de los EE.UU., Europa occidental, incluso Roma. Por esa razón se aseguraba que con el fin de la Guerra Fría y la caída del Muro de Berlín, la teología de la liberación había llegado a su fin (Valtierra, en prensa).

2 Para autores como Enrique Dussel o Phillip Berryman parte de la explicación de la Teología de la liberación se debe a la crisis social que se acentuó en América Latina a inicios de 1960 y es allí donde la Iglesia latinoamericana empezó a analizar y pensar en su papel social, pero más activo. Sin embargo, hubo más acontecimientos que fortalecieron esta reflexión-acción: el Concilio Vaticano II (1962-1965) iniciado por el papa Juan XXIII. Antes de esta reforma eclesiástica los católicos tenían como principal deber permanecer "en estado de gracia y alcanzar el cielo" (Berryman, 2014, p. 20), en lugar de acentuar más la heterogeneidad de la Iglesia, poniendo al día el discurso político y la perspectiva de misión de la Iglesia frente al acelerado cambio cultural, social y político que conlleva lo que se concibe como modernidad. El contenido del Concilio Vaticano II fue una ruptura con el viejo orden. El otro acontecimiento de importancia fue la Conferencia Episcopal Latinoamericana de Medellín, Colombia (1968), que, en esencia, sintetizó el mensaje conciliar y lo adaptó a América Latina.

3 En la acción pastoral con bases firmes de la teología de la liberación puede encontrarse la catequesis integradora y pastoral indígena de Samuel Ruiz García que ha trascendido hasta el día de hoy en un acompañamiento constante a los diferentes pueblos indígenas del Estado de Chiapas en materia agroecológica, pero también en el respeto a la diversidad religiosa con la denominada teología india. En Guatemala la presencia de la teología india también es testimonio de una pastoral con bases liberacionistas en que han participado importantes órdenes religiosas como la Compañía de Jesús, la Orden de Predicadores y los Salesianos.

4 Se puede fechar a partir de 1920 la generalización del uso de la dominación gamonal como una expresión para definir el ejercicio del poder local en el Ecuador. La primera referencia que se dispone, está ubicada en el siglo XVIII, cuando el vocablo gamonal apareció mencionado en un juicio de la sublevación de indios de Riobamba. Con esta palabra, se estaba designando a algún sector dominante. Es decir, a algún grupo o familia que posee poder local en lo económico, cultural, etc. (Ibarra, citado en Illicachi, 2006, p. 6).

5 Cabe señalar que la metodología utilizada a lo largo de esta investigación involucra el esfuerzo colectivo o minka etnográfica. Hacemos una especial mención al Centro de Solidaridad Andina (CEDESA) y a Homero García, Joaquín Pintag, Tamya Illicachi, Gerardo Nieves y Estuardo Gallegos, por permitirnos el acceso a la revisión de archivos, incluso personales, entrevistas y revisión de literatura especializada. Además, el trabajo de campo etnográfico se basó en el uso de las entrevistas personales, trípticos, afiches, hojas volantes, folletos y actas dispersas. Otro de los aspectos metodológicos que es importante tomar en cuenta es el de los conocimientos situados, en el sentido de reflexionar el por qué y desde qué posición nos hemos dado 
a la tarea de escribir, pues como menciona Carmen Martínez Novo al inicio de su artículo Religión, política e identidad: "comenzar con algunos datos personales para transparentar mi posición con relación a este tema” (2009, p. 21); admitimos que las páginas desarrolladas en esta investigación son una urdimbre de los continuos encuentros y desencuentros de las experiencias personales y colectivas entre nosotros como autores, en que hemos conjugado nuestros intereses en temas relacionados con la liberación y la religión desde distintos contextos espaciales y temporales.

6 Leonidas Proaño, nació en Imbabura en 1910. Fue nombrado sacerdote en 1936 y obispo de Riobamba en 1954. En 1976 fue llevado a la cárcel por la Dictadura militar junto a 16 obispos latinoamericanos. En 1986 fue nominado como candidato al Premio Nobel de la Paz. Fallece el 31 de agosto de 1988 a los 78 años.

7 Achille Mbembe (2011) esgrime las categorías: necropoder y necropolítica para examinar los mecanismos por los que se establece y mantiene un control sobre quién puede vivir y quién debe morir. Para Mbembe, todos los Estados modernos clasifican las vidas de sus sujetos en un sistema donde la muerte de ciertos cuerpos y almas no es sólo esperable, sino incluso rentable.

8 Según Foucault, el Estado nazi ha sido el ejemplo más logrado de Estado que ejerce su derecho a matar (Achille Mbembe, 2011, p. 23). Aunque, en el contexto de Chimborazo también funcionaba el derecho de matar; por ejemplo, en 1872 el líder indígena Fernando Daquilema fue ejecutado públicamente, exhibiendo a sus pares, no obstante de haber emitido un indulto desde el ejecutivo.

9 En tiempos de Gramsci, las principales instituciones de hegemonía eran la escuela y las iglesias. En nuestra época son los medios de comunicación masiva (Kohan, 2013, p. 11).

10 La categoría contrahegemonía da cuenta de los elementos para la construcción de la conciencia política autónoma en las diversas clases y sectores populares. Plantea los escenarios de disputa en el paso de los intereses particulares hacia los intereses generales, como proceso político clave hacia un bloque social alternativo (Gonzáles, 2003).

11 Con fines ilustrativos algunos conceptos: liberar o libertar significa quitar obstáculos u obligaciones; liberto esclavo dado libertad; libertar es dar libertad. Derivado de liberto; libertador es el que liberta a otros; libertad es el estado o cualidad de poder operar sin obstáculos; liberal es la persona que piensa sin obstáculos; libertario es el partidario de una libertad absoluta (Proaño, 1974).

12 El concepto “desarrollo" era uno de los componentes de la Teoría de la Dependencia surgida en América Latina en los años sesenta como alternativa a la teoría de modernización.

13 Éxodo es la salida de Egipto, que en la Biblia es la gran hazaña de Dios. La salida de país de la esclavitud en camino hacia la tierra prometida. Dios libera a su pueblo "con gran poder, mano fuerte y brazo extendido", abriéndole un camino en el mar (Biblia, 2005, p. 68).

14 Decía Proaño: “Así como en otro tiempo Israel, el primer pueblo, experimentaba la presencia salvífica de Dios cuando lo liberaba de la opresión de Egipto, cuando lo hacía pasar el mar y lo conducía hacia la tierra de la promesa, así también nosotros, nuevo pueblo de Dios, no podemos dejar de sentir su paso que salva, cuando se da el verdadero desarrollo, que es el paso, para cada uno y para todos, de condiciones de vida más humanas (Proaño, 1974, p. 5).

15 La idea de que una transformación social fundamental no ocurre nunca sin violencia, no era nueva; era parte de las tradiciones emancipatorias radicales heredadas del siglo XIX. Estas tradiciones, afirmaban todas ellas que los privilegiados nunca 
ceden el poder real tranquila y/o voluntariamente; el poder le es siempre arrancado (Wallerstein, 2010, p. 37).

16 Al decir de Immanuel Wallerstein (2010), Fanon parece defender, esencialmente, tres tesis sobre la violencia, como táctica política: primera tesis, dentro de un mundo colonial que es "maniqueísta", la fuente original de la violencia se encuentra en los recurrentes actos violentos del propio colonizador; segunda tesis, es que la violencia transforma, tanto la psicología social como la cultura política de todos aquellos que fueron colonizados y, tercera tesis, el camino aparentemente irreversible de la liberación nacional y de la liberación humana.

17 Para Fanon (2007) en su libro "Los condenados de la tierra" aborda la sustitución de los explotadores extranjeros por los nativos, haciendo hincapié sobre todo en la luchas de clases. Mientras para Hugo Burgos, el colonialismo interno constituyó una expresión de relaciones sociales que determinaban el retraso tecnológico y científico, la explotación económica y el control político no solo de los "indios" sino también de los otros grupos y clases (1997, p. 333).

\section{Bibliografía}

ACHILLE MBEMBE

2011 Necropolítica, sobre el gobierno de privado indirecto. Barcelona: Melusina.

2016 Crítica de la razón negra. Buenos Aires: Futuro Anterior.

AGAMBEN, Giorgio

2010 Lo que queda de Auschwitz. El archivo y el testigo. Homo Sacer III. Madrid: Pretextos.

BERRYMAN, Phillip

2014 Teología de la liberación. México: Siglo Veintiuno.

BAYLACH, José-Oriol

1979 La controvertida personalidad de Mons. Leonidas Proaño, en Leonidas Proaño, 25 años obispo de Riobamba. Lima-Perú: Centro de Estudios y Publicaciones CEP y Ecuador: Instituto Diocesano de Pastoral de Riobamba.

BRETÓN, Víctor

2001 Cooperación al desarrollo y demandas étnicas en los andes ecuatorianos. Ensayo sobre indigenismo, desarrollo rural y neoindigenismo. Quito: FLACSO-Ecuador.

BOURDIEU, Pierre

2008 Capital cultural, escuela y espacio social. México: Siglo veintiuno.

1996 Sobre la televisión. Barcelona: Anagrama.

BURGOS, Hugo

1997 Relaciones interétnicas en Riobamba. Quito: Corporación Editora Nacional. CASTRO-GÓMEZ, Santiago

2014 Descolonizar la universidad. La hybris del punto cero y el dialogo de saberes. En: Zulma Palermo (Comp.), Des/colonizar la universidad (pp. 69-84). Buenos Aires: Ediciones del Silgo.

DE SOUSA SANTOS, Boaventura

2010 Enriquecer la democracia construyendo la plurinacionalidad. En: Mirian Lang y Alejandra Santillana (Comps.), Democracia, participación y socialismo (pp. 23-34). Quito: Rosa Luxemburg. 
FANON, Frantz

2007 Los condenados de la Tierra. México: Siglo veintiuno.

2011 Piel negra, máscaras blancas. Habana: Editorial Caminos.

FOUCAULT, Michel

1996 Genealogía del racismo. La Plata: Caronte.

2006 Defender la Sociedad. México: Siglo Veintiuno.

2011 Historia de la sexualidad. 1. La voluntad del saber. México: Siglo Veintiuno.

2010 Obras esenciales. Barcelona: Ediciones Paidós Ibérica.

FREIRE, Paulo

2013 La educación como práctica de la libertad. México: Siglo Veintiuno.

GONZÁLES, Ernesto

2003 Hegemonía, ideología y democracia en Gramsci. México: Instituto Tecnológico y de Estudios Superiores de Monterrey.

GONZÁLEZ, Pablo

2006 El colonialismo interno. Buenos Aires: CLACSO.

HIGUERA, Edison

2014 Negación del ser para el reconocimiento del otro. Sophia, colección de filosofía de la educación, 17(2), 139-158. Quito: Editorial Abya-Yala/Universidad Politécnica Salesiana.

\section{ILLICACHI, Juan}

2006 Catolicismo, protestantismo y movimiento indígena en Chimborazo, 19602005. Tesis de maestría. FLACSO: Quito.

2015a Racismo, neoracismo y educción. Universitas, XIII (22), pp. 95-115. Quito: Editorial Abya-Yala/Universidad Politécnica Salesiana.

2015b La educación intercultural bilingüe como proyecto epistémico de los movimientos indígenas en el Ecuador. Sophia, colección de filosofía de la educación, 18 (1), pp. 211-229. Quito: Editorial Abya-Yala/Universidad Politécnica Salesiana.

KOHAN, Néstor

2013 Antonio Gramsci. Editorial Latinoamericana: Guatemala.

LECHUGA, Graciela

2007 Foucault. México: Universidad Autónoma Metropolitana.

MARTÍNEZ, Caarmen

2009 La crisis del proyecto cultural del movimiento indígena. En: Repensando los movimientos indígenas (pp. 173-198). Quito: Facultad Latinoamérica de Ciencias Sociales.

MÁRQUEZ, José

2007 Gilles Deleuze-Michel Foucault. El continente fascinante de la filosofía. Medellín: El Caribe Editores.

MIGNOLO, Walter

2014 Desobediencia epistémica. Retórica de la modernidad, lógica de la colonialidad y gramática de la descolonialidad. México: Ediciones del Signo.

MODELO DEL SISTEMA DE EDUCACIÓN INTERCULTURAL BILINGÜE (MOSEIB). NELSON, Diane

2006 Un dedo en la llaga. Guatemala: Cholsamaj.

ORTEGA, Remberto y FERNÁNDEZ, Johny

2014 La Ontología de la educación como un referente para la comprensión de sí misma y del mundo. Sophia: colección de Filosofía de la Educación, 17(12), 37-57. Quito: Editorial Abya-Yala/Universidad Politécnica Salesiana. 
PROAÑO, Leonidas

1974 Educación liberadora. Quito: Corporación Editora Nacional.

1989 La cultura indígena. Quito: Fundación Pueblo Indio del Ecuador.

RAMOS, Miguel

s/a Introducción a la Biblia. Quito: Editorial Espiritual.

RESTREPO, Eduardo

2005 Políticas de la teoría y dilemas en los estudios de las colombias negras. Cauca: Universidad del Cauca.

SAID, Edward

2009 Orientalismo. México: Literaria.

TAMAYO, José

2000 Para aprender la teología de la liberación. Editorial Verbo Divino: Navarra.

VALTIERRA, Jorge

2017 La pastoral indígena y resistencia hacia la Teología India Cristiana en Chiapas, México. Sociedad y Religión. (en prensa).

VALVERDE, Clara

2015 De la necropolítica neoliberal a la empatía radical. Violencia discreta, cuerpos excluidos y repolitización. Barcelona: Icaria.

WALLERSTEIN, IMMANUEL

2010 Leer a Frantz Fanon en el siglo XXI. Revista Contrahistorias, la otra mirada de Clío, 14, 35- 42.

WALSH, Catherine

2017 Gritos, grietas y siembras de vida: Entretejeres de lo pedagógico y lo decolonial. En: Pedagogías decoloniales. Prácticas insurgentes de residir, (re) existir y (re) vivir (pp. 17-48). Quito: Editorial Abya-Yala.

ZAPATA, Patricia

2017 Leer a Fanon, medio siglo después. Buenos Aires: CLACSO.

Fecha de recepción del documento: 1 de agosto de 2017

Fecha de revisión del documento: 20 de agosto de 2017

Fecha de aceptación del documento: 15 de septiembre de 2017

Fecha de publicación del documento: 15 de enero de 2018 